\title{
The validation of the measurement of the mental and physical components of SF-12 in Iranian elderly
}

\author{
Ghasem Zare $^{1^{*}}$, Jaouad Alem ${ }^{2}$, and Fatemeh Zare
}

${ }^{1}$ Physical Education Department, Marvdasht Branch, Islamic Azad University, Marvdasht, Iran (gh.zare@gmail.com)

${ }^{2}$ École de Kinésiologie et des Sciences de la santé, Canada (jalem@laurentian.ca)

${ }^{3}$ Counselling Department, Marvdasht Branch, Islamic Azad University, Marvdasht, Iran (zare.f1366@gmail.com)

\begin{abstract}
This study aimed to assess the validity and reliability of the mental component summary (MCS) and physical component summary (PCS) of SF-12. 140 Iranian elderly aged 60 years and older from the general population (100 male vs 40 female) of the Shiraz city were recruited by convenient sampling. The questionnaire on quality of life (SF-12, two dimensions: the physical component $\alpha=0.68$; and the mental component $\alpha=0.71$ ) was used to collect the data analyzed with the AMOS software. According to the structural equation model (SEM), four subscales of SF-12 (emotional role, social function, vitality and mental health) can predict mental component summary (respectively: coefficient $=0.65,0.57,0.78$ and 0.90 ) and four subscales of SF-12 (general health, physical function, bodily pain and physical role) can predict physical component summary (respectively: coefficient $=0.58,0.70,0.74$ and 0.88 ). The goodness-of-fit indices showed that the model for predicting mental and physical components in the elderly was excellent $(\mathrm{X} 2 / \mathrm{df}=$ 1.61, $\mathrm{RMSEA}=0.07, \mathrm{CFI}=0.96$ and $\mathrm{NFI}=0.92$ ).
\end{abstract}

\section{INTRODUCTION}

Ageing leads to a higher probability of health complaints. Though, the consequences of these ailments could be prevented, in case the quality of life and health-related conditions of older people would be considered (Borglin, Jakobsson, Edberg, \& Hallberg (2005). medical, social and psychological problems could decrease elderly people activities and subsequently result in diminished healthrelated quality of life (HRQOL) (Canbaz, SÜNTER, Dabak, \& PEKŞEN, 2003).

It is estimated that by 2036 the number of elderly in Iran reaches over 10 million people ( $11 \%$ of the population). Due to a significant increase in the proportion of older adults in the population in Iran in the next few decades, the health care sector will be costly in the future (Mirzaie, \& Darabi, 2017).

One of the primary components of general well-being is mental well-being. In old age, psychological health is associated with physical activity energy expenditure (PAEE, $\left.\mathrm{r}=0.26^{* *}\right)$ and sedentary time $\left(\mathrm{r}=-0.16^{*}\right)$ and moderate-intensity activity $\left(\mathrm{r}=0.21^{* *}\right)$ (Fox, Stathi, McKenna, \& Davis, 2007).

In order to assess the mental and physical components of the health of the elderly, valid and reliable instruments are required. Measuring the elderly's mental and physical health conditions may not only advantage health outcomes and lessening disability and increase autonomy, but also make available valuable information for public health endeavours (Steptoe, Deaton, \& Stone, 2015).

SF-12 is a validated measurement to assess the HealthRelated Quality of Life (HRQoL), which includes two dimensions: a physical component summary (PCS, six items) and a mental component summary (MCS, six items) (Andrade, Andrade, de Oliveira Duarte, \& de Andrade, 2020). According to Ware, Kosinski, and Keller (1996), the SF-12 is an instrument to measure general quality of life with two dimensions and eight subscales, including: general health perceptions (1 item), role physical (two items), physical functioning (two items), and bodily pain (1 item) as physical component summary (PCS), role emotional (two items), social functioning (1 item), vitality (1 item), and mental health (two items) as mental component summary (MCS).

Montazeri, Goshtasebi, Vahdaninia, \& Gandek (2005) developed a study to assess the psychometric qualities of Iranian version of SF-36. 4163 people aged 15 years and older in Tehran were recruited as the study sample. The reliability of the measurement calculated by Cronbach's alpha ranging from 0.77 to 0.90 except for the vitality subscale $(\alpha=0.65)$. Factor structure using oblique rotation showed the expected two-factor structure (physical and mental components).

Rohani et al. (2010) conducted a cross-sectional study to assess the psychometric qualities (validity and reliability) of Iranian SF-12 version 2. A total of 289 people aged 17 to 76 years in Tehran in 2006 were recruited. Using Exploratory Factor Analysis (EFA) by both varimax and oblique rotations and SEM with four models (model 1: two latent variables with 12 items, model 2: two latent variables with eight subscales, model 3: two latent variables with 12 items and cross-loading and model 4: two latent variables with eight subscales and crossloading) verified the existing two-component structure, PCS and MCS. Goodness of fit indices were excellent for four mentioned models $(\mathrm{SRMR}<0.08 ; \quad \mathrm{CFI}>0.90$, NNFI $>0.90$ and IFI $>0.90$ ). For reliability of PCS and MCS, Cronbach's alpha calculated and equals to 0.84 and 0.89 .

Tucker, Adams, Wilson (2010) did a study to compare the relationship between eight subscales of SF-36 with two dimensions of PCS and MCS which were come from two scoring algorithms: one from the original scoring method (Ware, et al., 1994) and the other from structural equation

\footnotetext{
*Corresponding author: gh.zare@gmail.com
} 
modelling. Data of 18492 Australian people over 15 years was collected. Fit indices showed that the measurement model of SF-36 and SF-12 has an excellent fit with RMSEA $<0.08$, Non-Normed Fit Index and the Comparative Fit Index was greater than 0.9. Based on structural equation modelling, factor coefficients showed that PCS and MCS components are more reliably aligned with the primary subscales of the SF-36.

Christensen, Ehlers, Larsen, \& Jensen (2013) conducted a study to measure the psychometric qualities of PCS and MCS of SF-12 in Denmark. The data of 26397 people above 25 years old were included in the analyses. By using confirmatory factor analysis (CFA) the factor structure of the model was examined. The Cronbach's alpha for PCS (0.90) and MCS (0.85) showed high reliability of the model. The EFA gave a two-factor structure. Model-fit values showed the acceptable validation of $\mathrm{CFA}(\mathrm{GFI}=0.95$, $\mathrm{AGFI}=0.90$, and $\mathrm{CFI}=$ 0.94).

In this study, by using structural equation modelling (SEM), validating of SF-12 measurement based on Iranian population data were tested.

The purpose of the present study is therefore to validate the mental and physical component of SF-12 in the elderly people.

\section{Methods}

This study is cross-sectional which its data was derived from Zare's study (2016).140 Iranian elderly aged 60 years and older from the general population (100 male vs 40 female) of the Shiraz city were recruited by convenient sampling. The questionnaire on quality of life (SF-12, two dimensions: physical component $\alpha=0.66$; and mental component $\alpha=0.71$ ) was used to collect the data. Variance-based structural equation modelling (SEM) using the partial least squares (PLS) was used to analyze the data. The mean age was 70 years. The majority of individuals were illiterate $(39 \%)$ or have gone to school for five years $(23 \%)$. Most people were married and female. More demographic characteristics can be seen in Table 1. Correlation between subscales of mental and physical components of quality of life was determined by Pearson correlation. SEM was used to validate the model of prediction of MCS and PCS. To assess the goodnessof-fit (GOF) of the model, maximum-likelihood estimation was used. Based on Hair et al. (2010), the use of four or five fit indices provides adequate evidence of model fit. To analyze the overall model fit, several GOF indicators were used: Chi-square divided by degree of freedom (X2/df), goodness-of-fit index (GFI), comparative fit index (CFI), normed fit index (NFI) and the root mean square error of approximation (RMSEA). The values of $\mathrm{X} 2 / \mathrm{df}$ less than 3 is acceptable. For GFI, CFI and NFI values above 0.9 were considered acceptable. The values of RMSEA below 0.08 would be considered reasonable. All the analyses were done using SmartPLS version 3, SPSS and Amos.

\section{Results}

The correlation between subscales of both mental and physical components of quality of life are shown in Table
2 and 3. The emotional, social function, vitality, and mental health subscales of QOL correlate with the MCS $\left(\mathrm{r}=0.46^{* *}, 0.63 * *, 0.79 * *\right.$ and $0.89 * *$, reactively) and general health, physical function, bodily pain and physical role subscales of QOL were related to the PCS $(\mathrm{r}=0.63 * *$, $0.75 * *, 0.78 * *$ and $0.78 * *$, respectively).

Table 1. The characteristics of the study sample $(n=140)$

\begin{tabular}{ll}
\hline Variable & n (\%) \\
\hline Age, year, M (SD) & $70(9)$ \\
\hline Gender, $\mathbf{n}(\%)$ & $100(71)$ \\
\hline Male & $40(29)$ \\
\hline Female & \\
\hline Level of education, n (\%) & $54(39)$ \\
\hline Illiterate & $32(23)$ \\
\hline Primary school, five years & $8(6)$ \\
\hline Secondary school, eight years & $20(14)$ \\
\hline High school diploma, 12 years & $26(19)$ \\
\hline University degree, 16 years & $118(84)$ \\
\hline Living condition, $\mathbf{n}(\%)$ & $22(16)$ \\
\hline Live with someone & $32.9(7.3)$ \\
\hline Live alone & $13.6(3.4)$ \\
\hline SF-12, M (SD) & $19.5(5.2)$ \\
\hline PCS
\end{tabular}

SEM analysis with a measurement model of the Iranian version of the SF-12 in the elderly was conducted to assess the confirmatory factor analysis (CFA). Figure 1 depicts the factor loading on each item. In addition, according to Table 4, the results of the subscales loadings explained that all the regression coefficients in the model had moderate to strong associations with the respective component. The greatest path coefficient was from MCS to mental health (0.90), and the smallest one was from MCS to social function (0.57). The variance explained by the Iranian version of the SF-12 for PCS was 0.77 and for MCS was 0.68 .

Table 5 summarizes the results of the goodness of fit indices for the model. SEM results showed that the model exceeded the sensitivity criteria of the goodness of fit. In addition, the factor loadings in the model showed that all items of SF-12 were more highly loaded on the respective subscales. 
Table 2. Correlation Matrix between subscales of the elderly's mental component summary $(\alpha$ Cronbach $=0.71)$

\begin{tabular}{cccccc}
\hline & variables & $\mathbf{1}$ & $\mathbf{2}$ & $\mathbf{3}$ & $\mathbf{4}$ \\
\hline $\mathbf{1}$ & Emotional & 1 & & & \\
\hline $\mathbf{2}$ & $\begin{array}{c}\text { Social } \\
\text { function }\end{array}$ & 0.13 & 1 & & \\
\hline $\mathbf{3}$ & Vitality & $0.27^{* *}$ & $.29 * *$ & 1 & \\
\hline $\mathbf{4}$ & $\begin{array}{c}\text { Mental } \\
\text { health }\end{array}$ & $0.30^{* *}$ & $0.38^{* *}$ & $0.63^{* *}$ & 1 \\
\hline $\mathbf{5}$ & MCS & $0.46^{* *}$ & $0.63^{* *}$ & $0.79^{* *}$ & $\begin{array}{c}0.89^{*} \\
*\end{array}$ \\
\hline
\end{tabular}

Table 3. Correlation Matrix between subscales of the elderly's physical component summary $(\alpha$ Cronbach $=0.68)$

\begin{tabular}{cccccc}
\hline & variables & $\mathbf{1}$ & $\mathbf{2}$ & $\mathbf{3}$ & $\mathbf{4}$ \\
\hline $\mathbf{1}$ & $\begin{array}{c}\text { General } \\
\text { health }\end{array}$ & 1 & & & \\
\hline $\mathbf{2}$ & $\begin{array}{c}\text { Physical } \\
\text { function }\end{array}$ & $0.29^{* *}$ & 1 & & \\
\hline $\mathbf{3}$ & $\begin{array}{c}\text { Bodily } \\
\text { pain }\end{array}$ & $0.36^{* *}$ & $0.59^{* *}$ & 1 & \\
\hline $\mathbf{4}$ & $\begin{array}{c}\text { Physical } \\
\text { role }\end{array}$ & $0.36^{* *}$ & $0.42^{* *}$ & $0.34^{* *}$ & 1 \\
\hline $\mathbf{5}$ & PCS & $0.63^{* *}$ & $0.75^{* *}$ & $0.78^{* *}$ & $0.78^{* *}$ \\
\hline
\end{tabular}

Table 4: Path standardized coefficients based on SEM

\begin{tabular}{cccc}
\hline & & & Estimate \\
\hline Physical role & $\leftarrow$ & PCS & 0.88 \\
\hline Bodily pain & $\leftarrow$ & PCS & 0.74 \\
\hline Physical function & $\leftarrow$ & PCS & 0.70 \\
\hline General health & $\leftarrow$ & PCS & 0.58 \\
\hline Mental health & $\leftarrow$ & MCS & 0.90 \\
\hline Vitality & $\leftarrow$ & MCS & 0.78 \\
\hline Social function & $\leftarrow$ & MCS & 0.57 \\
\hline Emotional role & $\leftarrow$ & MCS & 0.65 \\
\hline
\end{tabular}

Table 5. The goodness of fit indices of the model of Iranian SF-12 by SEM analysis in the elderly $(n=140)$

\begin{tabular}{cccccc}
\hline indices & X2 & X2/df & CFI & NFI & RMSEA \\
\hline & 20.94 & 1.61 & 0.96 & 0.92 & 0.07 \\
\hline
\end{tabular}

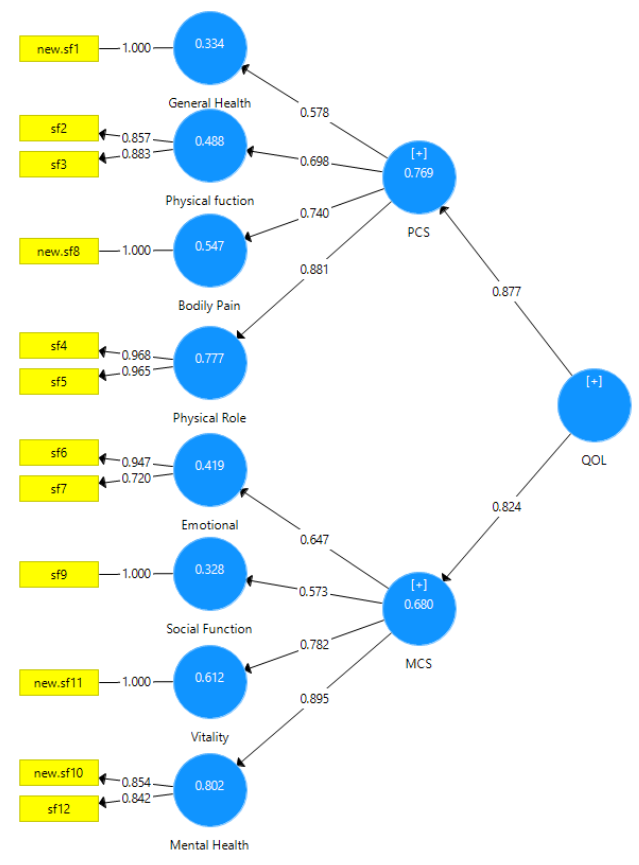

Figure 1. Structure of SF-12 with two dimensions and eight subscales in the Iranian elderly based on SEM analysis

\section{Discussion}

This study aimed to analyze the psychometric qualities (reliability and validity) of the SF-12 questionnaire using SEM among elderly people in Shiraz, Iran. The results indicated the reliability and validity of the SF-12 measurement. Other studies can use this valid instrument to assess the quality of life in the elderly population.

Although there are some other studies (Rohani et al., 2010; Christensen et al., 2013; Montazeri et al., 2009) performing similar research with the purpose of validating SF-12 in a general population, this study and its statistical method is unique.

The factor structure found in this study (two factors) was different from Bentur and King (2010) that found three underlying factors. This contradiction was reasonable because of linguistic and cultural difference (Montazeri et al. 2005), and it can be concluded that since the sample of this study was elderly, and their response to the SF-12 questions were relatively homogeneous, the output of EFA analysis was two factors.

The two-factor structure was confirmed with the measurement model of SEM using SmartPLS, supporting the original conceptual model of the SF-12 tool. This study only used Cronbach's alpha to measure reliability; therefore it is suggested performing test-retest or responsiveness to change as complementary reliability analyses. 
One limitations of this study is the lack of another measurement like SF-36 as a supplement to the SF-12 scores. Further studies should verify the psychometric qualities of SF-12 in other large samples in Iran.

\section{References}

Bentur, N., \& King, Y. (2010). The challenge of validating SF-12 for its use with community-dwelling elderly in Israel. Quality of Life Research, 19(1), 91-95.

Borglin, G., Jakobsson, U., Edberg, A. K., \& Hallberg, I. R. (2005). Self-reported health complaints and their prediction of overall and health-related quality of life among elderly people. International journal of nursing studies, 42(2), 147-158.

Canbaz, S., SÜNTER, A. T., Dabak, S., \& PEKŞEN, Y. (2003). The prevalence of chronic diseases and quality of life in elderly people in Samsun. Turkish Journal of Medical Sciences, 33(5), 335-340.

Christensen, L. N., Ehlers, L., Larsen, F. B., \& Jensen, M. B. (2013). Validation of the 12-item shortform health survey in a sample from region Central Jutland. Social indicators research, 114(2), 513-521.

Fox, K. R., Stathi, A., McKenna, J., \& Davis, M. G. (2007). Physical activity and mental well-being in older people participating in the Better Ageing Project. European journal of applied physiology, 100(5), 591-602.

Hair, J. F., Black, W. C., Babin, B. J., \& Anderson, R. E. (2010). Multivariate data analysis (7th edn) (p. 800). Prentice-Hall. Retrieved from http://www.amazon.com/Multivariate-Data-Analysis7th-Edition/ dp/0138132631

Mirzaie, M., \& Darabi, S. (2017). Population ageing in Iran and rising health care costs. Iranian Journal of Ageing, 12(2), 156-169.

Montazeri, A., Goshtasebi, A., Vahdaninia, M., \& Gandek, B. (2005). The Short-Form Health Survey (SF36): translation and validation study of the Iranian version. Quality of life research, 14(3), 875-882.

Rohani, C., Abedi, H. A., \& Langius, A. (2010). The Iranian SF-12 Health Survey version 2 (SF-12v2): Factorial and convergent validity, internal Consistency and test-retest in a healthy sample. Iranian Rehabilitation Journal, 8(2), 4-14.

Steptoe, A., Deaton, A., \& Stone, A. A. (2015). Subjective wellbeing, health, and ageing. The Lancet, 385(9968), 640-648. doi:10.1016/S01406736(13)61489-0

Tucker, G., Adams, R., \& Wilson, D. (2010). New Australian population scoring coefficients for the old version of the SF-36 and SF-12 health status questionnaires. Quality of Life Research, 19(7), 10691076.

Ware Jr, J. E., Kosinski, M., \& Keller, S. D. (1996). A 12-Item Short-Form Health Survey: construction of scales and preliminary tests of reliability and validity. Medical care, 220-233. 
